\title{
MATEMÁTICA EM SEÇÕES RECREATIVAS DO PERIÓDICO O ECO
}

\author{
Mathematics in Recreational Sections of The Echo Magazine
}

\author{
Silvio Luiz Martins Britto ${ }^{1}$ \\ Malcus Cassiano Kuhn ${ }^{2}$
}

\begin{abstract}
Resumo: O artigo tem por objetivo abordar a Matemática em seções recreativas do periódico O Eco, editado pelo Colégio Anchieta, de Porto Alegre, no período de abril de 1914 até o final de 1969. A questão de pesquisa é: quais conhecimentos matemáticos estão presentes nas seções recreativas de $O E c o$ ? Como o tema se insere na História da Educação Matemática do Rio Grande do Sul, este estudo qualitativo e documental se ampara na pesquisa histórica. O públicoalvo do periódico era a comunidade escolar e a mocidade católica brasileira, apresentando-se conteúdos religiosos, morais e de formação geral. Nos mais de 50 anos de edição do periódico, foram identificadas cinco seções recreativas, com variados períodos de existência: Recreio, Para Pequenos Mathemáticos, Mata Tempo Intelectual, Para o Grande Concurso e Cantinho do Sábio. Nessas seções, foram encontradas perguntas, charadas, problemas, enigmas, curiosidades, palavras cruzadas e outras atividades de passatempo. A Matemática aparece em problemas, perguntas e curiosidades, valorizando o pensamento lógico-matemático dos leitores, premiando assinantes com soluções corretas. Os conhecimentos matemáticos envolvem aritmética, geometria, álgebra, grandezas e medidas, com foco no desenvolvimento de habilidades para cálculo, raciocínio lógico e resolução de problemas, envolvendo situações de forma instigante, provocativa e útil. Assim, os editores do periódico buscavam despertar o interesse e a curiosidade da juventude estudantil, contribuindo para a formação da juventude católica nos colégios onde $O$ Eco circulava.
\end{abstract}

Palavras-chave: História da Educação. Jesuítas. Revista. Matemática.

Abstract: The article aims to address Mathematics in recreational sections of The Echo magazine, edited by Anchieta School of Porto Alegre, from April 1914 to the end of 1969. The research question is what mathematical knowledge is present in the recreational sections of The Echo? As the theme is part of the History of Mathematical Education in Rio Grande do Sul, this qualitative and documentary study is supported by historical research. The target audience of the periodical was the school community and the Brazilian Catholic youth, presenting religious, moral and general education content. In the 50 plus years of publication of the magazine, five recreational sections have been identified with varied periods of occurrence: Recreation, For

\footnotetext{
${ }^{1}$ Doutor em Ensino de Ciências e Matemática pela Universidade Luterana do Brasil - ULBRA/Canoas/RS. Professor das Faculdades Integradas de Taquara - FACCAT/Taquara/RS. Membro do Grupo de Pesquisa Estratégias de Ensino para Educação Básica e Profissional. ORCID: http://orcid.org/0000-0001-5222-0126. Email: silviobritto@faccat.br

2 Doutor em Ensino de Ciências e Matemática pela Universidade Luterana do Brasil - ULBRA/Canoas/RS. Professor do Instituto Federal de Educação, Ciência e Tecnologia Sul-rio-grandense - IFSul Câmpus Lajeado/RS. Líder do Grupo de Pesquisa Estratégias de Ensino para Educação Básica e Profissional. ORCID: http://orcid.org/0000-0002-6001-2324. E-mail: malcuskuhn@ifsul.edu.br
} 
Young Mathematicians, Kills Intellectual Time, For the Great Competition and Sage's Corner. In these sections questions, riddles, problems, puzzles, curiosities, crosswords and other pastime activities were found. Mathematics appears in problems, questions and curiosities, valuing the reader's logical-mathematical thinking, rewarding subscribers with correct solutions. Mathematical knowledge involves arithmetic, geometry, algebra, quantities and measures, with a focus on developing skills for calculus, logical reasoning and problem solving, involving situations in a thought-provoking, challenging and useful way. Thus, the editors of the magazine sought to arouse the interest and curiosity of young students, contributing to the formation of Catholic youth in the schools where The Echo circulated.

Keywords: History of Education. Jesuits. Magazine. Mathematics.

\section{Introdução}

Os trabalhos desenvolvidos pelas ordens religiosas que chegaram ao Rio Grande do Sul (RS) após a segunda metade do século XIX deixaram relevantes contribuições. Dentre essas ordens, destacam-se os Jesuítas, os quais desenvolveram trabalhos missionários inicialmente junto às colônias de imigrantes alemães católicos e, posteriormente, com a criação de uma rede de Ginásios e Seminários, contribuindo para a formação da juventude gaúcha. Entre os educandários criados, encontra-se o Colégio Anchieta, com sede em Porto Alegre/RS.

Este artigo tem por objetivo abordar a Matemática nas seções recreativas do periódico $O E c o$, editado pelo Colégio Anchieta, de Porto Alegre, no século passado. A questão da pesquisa versa sobre quais conhecimentos matemáticos estão presentes nas seções recreativas de $O$ Eco. Trata-se de um recorte do estudo iniciado durante a elaboração da tese $O$ ensino da aritmética nas escolas paroquiais católicas e no Ginásio Nossa Senhora da Conceição de São Leopoldo nos séculos XIX e XX sob a ótica dos Jesuítas (BRITTO, 2016), e aprofundado no estágio Pós-Doutoral no Programa de Pós-graduação em Ensino de Ciências e Matemática (PPGECIM), da Universidade Luterana do Brasil (ULBRA).

O periódico $O$ Echo foi editado pelo Colégio Anchieta, por meio da Typographia do Centro, localizada em Porto Alegre, no período de abril de 1914 a dezembro de 1931. A partir de 1932, passou a ser denominado $O E c o$, devido à reforma ortográfica ${ }^{3}$. Seu público-alvo era a comunidade escolar e a mocidade católica brasileira, pois, segundo os editores, não havia periódicos para os jovens estudantes. $O$ Eco apresentava cultura geral e valores católicos, por isso era destinado para os jovens dessa confessionalidade.

Com o objetivo de analisar as edições do periódico $O E c o$, com ênfase à Matemática nas seções recreativas, além do referencial teórico-metodológico, são apresentadas a história do periódico e a abordagem de conhecimentos matemáticos presentes nessas seções. Assim, pretende-se compartilhar relevantes contribuições da ordem dos Jesuítas na formação da sociedade gaúcha e brasileira.

\section{Percurso metodológico da investigação}

Para atingir o objetivo desta investigação, foi realizada uma pesquisa qualitativa que, de acordo com Prodanov e Freitas (2013, p. 70), "preocupa-se mais com o processo do que com o

\footnotetext{
${ }^{3}$ Em 30 de abril de 1931, entraram em acordo a Academia Brasileira de Letras e a Academia das Ciências de Lisboa, no sentido de ser adotado um único sistema ortográfico no Brasil e em Portugal. Esse entendimento teve a aprovação oficial do Governo Provisório, por força do Decreto nº 28.128, de 15 de junho de 1931.
} 
produto. $\mathrm{Na}$ análise dos dados, não há preocupação em comprovar hipóteses previamente estabelecidas, porém estas não eliminam a existência de um quadro teórico que direcione a coleta, a análise e a interpretação dos dados". Ademais, a pesquisa qualitativa:

\begin{abstract}
Considera que há uma relação dinâmica entre o mundo real e o sujeito, isto é, um vínculo indissociável entre o mundo objetivo e a subjetividade do sujeito que não pode ser traduzido em números. A interpretação dos fenômenos e a atribuição de significados são básicas no processo de pesquisa qualitativa. Esta não requer o uso de métodos e técnicas estatísticas. O ambiente natural é a fonte direta para coleta de dados e o pesquisador é o instrumento-chave. Tal pesquisa é descritiva. Os pesquisadores tendem a analisar seus dados indutivamente. $O$ processo e seu significado são os focos principais de abordagem. (PRODANOV; FREITAS, 2013, p. 70).
\end{abstract}

Fazendo uso da abordagem qualitativa de pesquisa, investigou-se o periódico $O$ Eco. Foram realizadas visitas ao acervo particular do professor Luiz Osvaldo Leite ${ }^{4}$, em Porto Alegre, onde se encontram as edições do periódico. Ao pesquisá-las, compilaram-se as cinco seções recreativas: Recreio, Para Pequenos Mathemáticos, Mata Tempo Intelectual, Para o Grande Concurso e Cantinho do Sábio. Esse levantamento foi feito tendo em vista a posterior análise à luz do referencial teórico-metodológico. Acerca da metodologia do estudo de documentos, Cellard (2008) destaca que:

[...] o documento escrito constitui uma fonte extremamente preciosa para todo pesquisador. Ele é, evidentemente, insubstituível em qualquer reconstituição referente a um passado relativamente distante, pois não é raro que ele represente a quase totalidade dos vestígios da atividade humana em determinadas épocas. Além disso, muito frequentemente, ele permanece como o único testemunho de atividades particulares ocorridas num passado recente. (CELLARD, 2008, p. 295).

Como a temática investigada neste artigo se insere na História da Educação Matemática no Rio Grande do Sul, busca-se o suporte para discussão na pesquisa histórica. No âmbito da História da Educação no estado gaúcho, os trabalhos de Kreutz (1991, 1994), Rambo (1994, 1996) e Weiduschadt $(2007,2012)$ são destaques. Já na História da Educação Matemática no Rio Grande do Sul, destacam-se as pesquisas de Mauro (2005), Wanderer (2007), Kuhn (2015), Britto (2016), Kuhn e Bayer (2017a, 2017b) e Britto, Bayer e Kuhn (2020).

\title{
3 Referencial teórico-metodológico
}

Conforme Prost (2008), os fatos históricos são constituídos a partir de traços, de rastros deixados no presente pelo passado, ou seja, um fato não é outra coisa que o resultado de uma elaboração, de um raciocínio, a partir das marcas do passado. $\mathrm{O}$ autor considera o trajeto da produção histórica um interesse de pesquisa, a formulação de questões históricas legítimas, um trabalho com os documentos (edições do periódico $O E c o$ ) e a construção de um discurso que seja aceito pela comunidade.

\footnotetext{
${ }^{4}$ Graduado em Filosofia e Teologia pela UNISINOS e UFRGS. Atuou na área de Filosofia, com ênfase em História da Filosofia, Ética e Psicologia. Foi diretor do Instituto de Psicologia da UFRGS e professor Emérito dessa Instituição desde 2008. Foi aluno do Colégio Anchieta de 1944 a 1950 e atuou como professor nessa instituição de 1956 a 1959 e de 1965 até a década de 1980.
} 
Certeau (1982) define o fazer história no sentido de pensá-la como uma produção. Para o autor, a história, como uma produção escrita, tem a tripla tarefa de convocar o passado que já não está em um discurso presente, mostrar as competências do historiador e convencer o leitor. Dessa forma, a prática histórica é uma prática científica na medida em que inclui a construção de objetos de pesquisa, o uso de uma operação específica de trabalho e um processo de validação dos resultados obtidos por uma comunidade.

O trabalho do historiador, de acordo com Certeau (1982), não se limita a produzir documentos, textos em uma nova linguagem. Isso ocorre porque, no seu trajeto de pesquisa, há um diálogo constante do presente com o passado, e o produto desse diálogo consiste na transformação de objetos naturais em cultura. Nesse sentido, é preciso considerar:

\begin{abstract}
A imprensa é um corpus documental de vastas dimensões, pois se constitui em um testemunho vivo dos métodos e concepções pedagógicas de uma época e da ideologia moral, política e social de um grupo profissional. É um excelente observatório, uma fotografia da ideologia que preside. Nessa perspectiva, é um guia prático do cotidiano educacional e escolar, permitindo ao pesquisador estudar o pensamento pedagógico de um determinado setor ou de um grupo social a partir da análise do discurso veiculado e da ressonância dos temas debatidos, dentro e fora do universo escolar. (CATANI; BASTOS, 1997, p. 6).
\end{abstract}

Vale ressaltar os diversos formatos que a imprensa pedagógica pode assumir. Segundo Hernandez Díaz (2015), entre esses formatos, temos os seguintes: livros didáticos, manuais escolares, coleções dirigidas a professores, revistas, jornais, entre outros. Tendo como foco as revistas, Serra (2010) afirma que o trabalho com periódicos educacionais:

\footnotetext{
Possibilita a reconstrução histórica das práticas específicas desenvolvidas pelos autores, como também permite redesenhar os leitores visados por tais práticas, portanto a importância do estudo dos periódicos na sua materialidade. A partir do próprio impresso é possível recompor os projetos específicos como estratégias que visam a públicos leitores característicos. (SERRA, 2010, p. 25).
}

Conforme Valente (2007), há uma infinidade de materiais que, junto com os livros didáticos, podem permitir a composição de um quadro da Educação Matemática de outros tempos. Para o autor, realizar o estudo histórico da Matemática escolar exige que se devam considerar os produtos dessa cultura do ensino de Matemática, os quais deixaram traços que permitem o seu estudo, como o periódico $O E c o$, principal fonte documental dessa investigação.

\title{
40 periódico $O$ Eco e sua história
}

A presença dos Jesuítas no estado gaúcho aconteceu em três momentos, conforme ilustrado na Figura 1: 


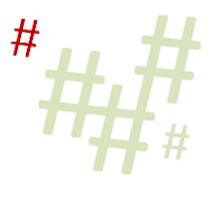

Figura 1 - Os Jesuítas no Rio Grande do Sul

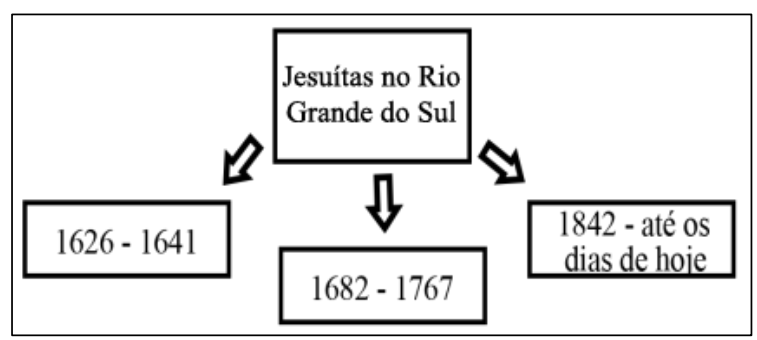

Fonte: Elaborado pelos autores, 2021.

Nos dois primeiros momentos (1626-1641 e 1682-1767), sua presença ocorreu junto aos índios ${ }^{5}$ Guaranis, nas chamadas reduções jesuíticas ${ }^{6}$. Suas ações foram significativas para a história do Rio Grande do Sul, destacando-se a introdução do gado e a fundação de cidades. Outro aspecto a ser destacado se trata dos legados artísticos e culturais marcados por suas construções e obras. Isso se verificou até a expulsão dos Jesuítas desse território e de seus domínios, dizimando a etnia Guarani (BRITTO; BAYER; KUHN, 2020).

O retorno dos Jesuítas ao Rio Grande do Sul, em 1842, constituiu o terceiro momento. Destacou-se pela ação missionária e pelo ensino, inicialmente, junto às colônias de imigrantes alemães. Aos poucos, os padres foram se aliando aos colonos e com os professores paroquiais, prestando assistência espiritual e promovendo melhorias do ensino nas escolas e na formação dos professores. Conforme Britto (2016), os Jesuítas pouco atuaram como professores, mas sim auxiliaram no planejamento e na execução de suas aulas a partir de encontros de formação, além da criação de uma escola normal, visando formar e qualificar os futuros professores. Segundo Rambo (1994), as escolas paroquiais estiveram sob o comando da ordem por, aproximadamente, 70 anos, contribuindo para melhoria da qualidade do ensino nas colônias de imigrantes.

Em 1869, os Jesuítas criaram o Colégio Nossa Senhora da Conceição ${ }^{7}$, em São Leopoldo, em nível secundário, constituindo-se um dos marcos no processo de instrução no RS. Objetivava-se, inicialmente, formar padres e professores para as comunidades rurais de imigrantes alemães. Com professores extremamente qualificados, em sua maioria, provenientes da Alemanha, devido ao Kulturkampf ${ }^{8}$, a escola colheu os resultados obtidos por seus alunos, durante os 43 anos de atividades. No campo da Matemática, identificou-se, segundo relatórios desse ginásio, a presença de livros didáticos elaborados pelos próprios padres Jesuítas do Colégio Conceição. Em 1911, o Colégio perdeu o status de ginásio equiparado, transformandose apenas em uma escola. No ano de 1912, encerrou suas atividades em São Leopoldo,

\footnotetext{
${ }^{5}$ Nome atribuído a alguns nativos levados por Colombo à Portugal, que ele chamou de índios, pois ele consideravaos habitantes das Índias.

6 A palavra "reduzir" era usada no sentido de purificar, limpar. [...] Assim o local onde ficavam os índios "reduzidos", ou seja, limpos pelo batismo, era chamado de redução (BRITTO; BAYER; KUHN, 2020).

${ }^{7}$ O Colégio Nossa Senhora da Conceição, após ser equiparado ao Ginásio Nacional D. Pedro II, em 1900, passa a chamar-se Ginásio Nossa Senhora da Conceição, sendo esse o primeiro Ginásio do RS (O ECO, 1965, v. 6). “O Colégio Conceição, fundado em 1870, tornou-se o mais famoso estabelecimento de ensino secundário do sul do Brasil, por onde passaram mais de 5000 alunos, dos quais muitos galgaram elevados postos da Igreja, governo, exército e polícia" (O ECO, 1940, v. 10, p. 299).

${ }^{8}$ Kulturkampf, ou luta pela cultura, foi um movimento anticlerical alemão do século XIX, iniciado por Otto von Bismarck, chanceler do Império Alemão, em 1872.
} 
concentrando-se nas ações da ordem no Anchieta, em Porto Alegre, pois a maioria dos estudantes do Colégio Conceição residia na capital gaúcha (BRITTO, 2016).

O Anchieta surgiu no ano de 1890, como externato do Colégio Conceição, em Porto Alegre (RELATÓRIO DO COLÉGIO ANCHIETA, 1914). Mantido e dirigido pelos padres da Companhia de Jesus, foi fundado como um simples colégio. No princípio, com a denominação de Colégio dos Padres, era destinado somente a meninos. No ano de 1897, o Colégio mudou de nome, passando a se chamar São José. A denominação que o faria entrar para história no RS, como Colégio Anchieta, aconteceu em 1901, em homenagem ao Padre José de Anchieta, um fiel intérprete e seguidor da espiritualidade de Santo Inácio de Loyola, fundador da congregação dos Jesuítas.

Segundo Leite (2005), em 1908, como estabelecimento independente, o Anchieta foi equiparado ao Colégio Dom Pedro II. Já em 1911, tornou-se estabelecimento autônomo, devido à reforma ocasionada pela Lei Orgânica do mesmo ano. A partir de 1942, a denominação do Colégio passou a ser Colégio Anchieta. “Após 1963, com o início da transferência dos alunos para o novo prédio, adotou-se o princípio da coeducação, com rapazes e moças estudando lado a lado, quando a tradição nos colégios confessionais mantinha a separação dos sexos" (COLÉGIO ANCHIETA, 1990, p. 47). O Colégio Anchieta ainda está em funcionamento e, no ano de 2021, completa 131 anos de atividades junto à comunidade porto-alegrense.

Em 1914, no seu sétimo ano de atividade de forma independente, o Anchieta, como é conhecido, passou a editar o periódico $O$ Echo, destinado à mocidade brasileira, abordando temas pertinentes em suas diferentes épocas de circulação. Sua publicação aconteceu pela Typografia do Centro, localizada em Porto Alegre, no período de abril de 1914 até o final de 1969. A partir de 1932, o periódico passou a ser denominado $O$ Eco devido à reforma ortográfica. Segundo Leite (2018), a designação do nome desse periódico se dá:

\footnotetext{
No sentido de que os ensinamentos ressoassem fortemente, produzissem eco nos jovens, nas famílias, em toda a população católica. Para os seus precursores, todos de origem alemã, essa deveria ter o mesmo efeito do eco produzido nos Alpes da Europa, onde, em sua maioria, tiveram sua infância. Nesses locais, os pastores caminhavam pelas montanhas e ao chamarem seus animais produziam sons, através de instrumentos que ecoavam por toda a região, sendo algo típico que a população costumava a ouvir. (LEITE, 2018, informação verbal ${ }^{9}$ ).
}

$O$ Eco tinha, inicialmente, circulação mensal e, posteriormente, circulação bimestral, destinado à comunidade escolar, principalmente, à mocidade brasileira, conforme inscrição na capa dos periódicos publicados, reunindo diversos temas, entre eles a Matemática. Na Figura 2, apresentam-se capas do periódico investigado em diferentes períodos, inicialmente com a denominação $O$ Echo, até dezembro de 1931 e depois, com a denominação $O$ Eco.

\footnotetext{
${ }^{9}$ Entrevista concedida por Luiz Osvaldo Leite, em Porto Alegre/RS, no dia 16 de março de 2018.
} 

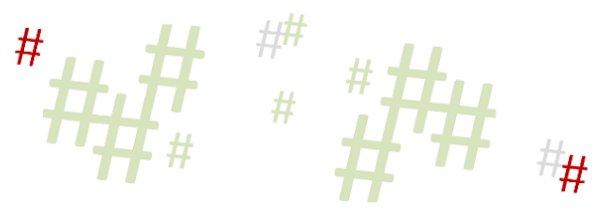

Figura 2 - Capas do periódico O Echo e $O$ Eco

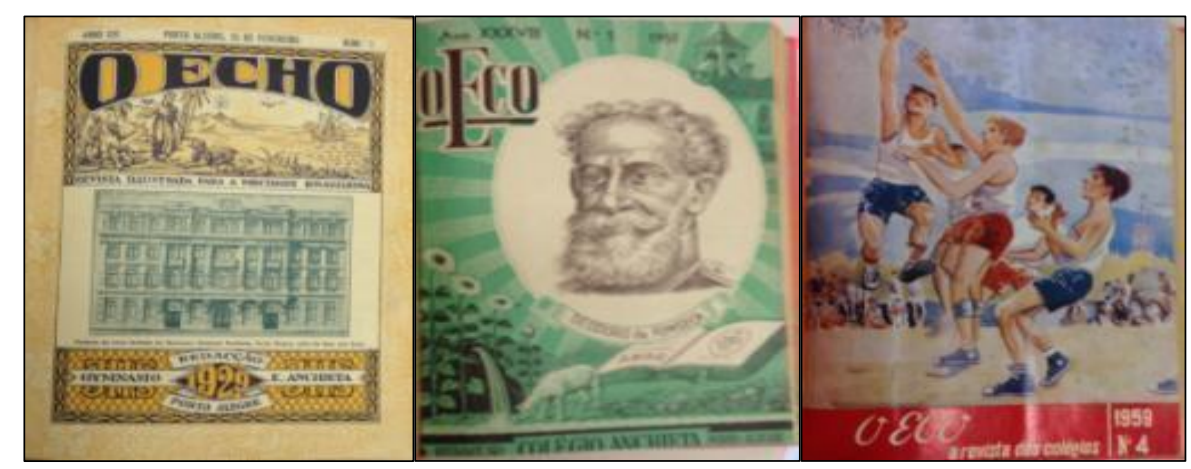

Fonte: $O$ Echo, 1929; O Eco, 1951; O Eco, 1959.

Nas duas primeiras décadas, a capa do periódico apresentou poucas alterações. Já nos anos seguintes, verificaram-se mudanças com frequência, apresentando, por exemplo, imagens de colégios pelo país (objetivando buscar assinantes), personagens da história do Brasil, esportes, profissões, pontos turísticos do Brasil, entre outros. O objetivo do periódico era:

\begin{abstract}
Há um número de revistas de diversas espécies: revistas para todos sem distincção de classe, e revistas especiaes para as diversas classes de pessoas. Há revistas jurídicas, há revistas médicas, há revistas commerciaes e industriaes, há revistas marítimas e militares, há revistas eclesiásticas, até para a infância há não sei quantas revistas infantis. Só a mocidade não tem uma revista própria, uma revista feita especialmente para ella. É uma lacuna por demais sensível e que urge preencher. Pois, essa classe poderosa em número, essa classe a que se dá tal importância que é chamada esperança da pátria, será admissível que careça de uma vantagem de que gozam os outros? Eis a origem do 'ECHO': nasceu da necessidade evidente de ter também a mocidade uma revista própria, exclusivamente sua. $(O E C H O, 1915 \text {, v. 1, p. } 1)^{10}$.
\end{abstract}

Editado, inicialmente, a cada vinte e cinco dias, com o primeiro número em fevereiro e o último em novembro de cada ano, o periódico totalizava 12 edições por ano. Um dos periódicos, normalmente o último do ano, abrangia dois números, já que em janeiro ele não era editado em virtude das férias escolares. A $1^{a}$ edição foi registrada em abril de 1914:

\footnotetext{
Sahiu à luz o $1^{\circ}$ número do $\mathrm{O}$ ECHO, revista mensal illustrada, na qual além de muitos colaboradores competentes que, em suas columnas, se dedicaram aos interesses da mocidade estudiosa do Brasil, os próprios alunos debaixo da direção de seus mestres, se estréam no manejo da pena. No suplemento 'Echos dos Collegios' trocam os jovens escriptores impressões e notícias que particularmente affectam a vida interna dos collegios. (RELATÓRIO DO COLÉGIO ANCHIETA, 1914, p. 28).
}

Cada edição era a continuação da anterior, inclusive na paginação, constatando-se que, durante $\mathrm{o}$ ano, eram publicadas de 350 a 430 páginas. $\mathrm{O}$ ano representava um volume, destacado em números romanos, e o mês era representado por um número natural. Os diferentes exemplares traziam artigos escritos e muitas gravuras, sendo sua estruturação semelhante em todas as edições. Nos 40 primeiros anos, a edição tinha um formato de $16 \mathrm{~cm}$ x $24 \mathrm{~cm}$. Já em 1963, o periódico ficou maior, com formato $32 \mathrm{~cm}$ x $23 \mathrm{~cm}$, passando a ter circulação bimestral.

${ }^{10} \mathrm{Na}$ citação, mantém-se a ortografia da fonte original. 
Os artigos no periódico $O$ Eco trazia poemas, notícias, reflexões de padres e professores, conferências, variedades, anedotas, contos, publicações de premiações de alunos por redação ou por competição esportiva, anúncios publicitários, Ciências, invenções, Artes, Astronomia, Matemática, reforma da Língua Portuguesa, descobertas. Além disso, após 1950, começaram a aparecer artigos direcionados à prática esportiva, como futebol, bola ao cesto, entre outros. De modo ilustrativo, apresenta-se o índice do volume 1 do periódico $O$ Eco de 1942 com as temáticas abordadas:

1 Assuntos Religiosos/ 2 Biografia e Traços Biográficos/ 3 Ciências Naturais e Técnicas/ 4 Artes, Matemática e Curiosidades/ 5 Indústria, Comércio, Etnografia e Viagens/ 6 História e Geografia/ 7 Assuntos Pedagógicos/ 8 História, Contos, Lendas e Anedotas/ 9 Poesias, Músicas e Aforismos/ 10 Linguística/ 11 Bibliografia/ Teatro e Humanismo. (OECO, 1942, v. 1, p. 8).

Acrescenta-se que, no periódico $O E c o$, também havia ilustrações, como fotografias de colégios, imagens de Papas, padres, alunos, ex-alunos, personagens da história do Brasil, santos da Igreja Católica, paisagens, ilustrações de textos, cenários de guerra, futebol e humor.

Conforme Leite (2018), O Eco encerrou a circulação em 1969, tendo como principal fator a falta de leitores. Inicialmente, em 1914, havia poucas publicações de periódicos, porém, com o decorrer do tempo, outros semelhantes passaram a ser publicados no Brasil, tais como: O Cruzeiro, A Cigarra e revistas em quadrinhos. Em virtude dos recursos financeiros, essas publicações eram mais atrativas visualmente, uma diferença em relação a $O E c o$.

Ainda de acordo com Leite (2018), o corpo de redatores era constituído por um diretor e por colaboradores voluntários, que enviavam artigos para as edições de $O E c o$. Já nos demais periódicos, havia uma equipe de redatores e técnicos, sendo todos remunerados. Acrescenta-se, segundo Leite (2018), que:

A revista ficou pesada demais para a época, até mesmo nós, como alunos do Anchieta, ela não despertava mais interesse, as matérias eram pesadas para a época. Até mesmo o espaço destinado a humor tornou-se de certa forma ingênuo. Os seminaristas adoravam, já os demais jovens não, até ridicularizavam. (LEITE, 2018, informação $\left.\operatorname{verbal}^{11}\right)$.

Diante desses fatores, o periódico não pôde mais se manter em circulação. Jornais diários, cronistas, fotos, diários esportivos e cinema ganharam seu espaço. Os novos periódicos traziam páginas sobre filmes e notícias e, com isso, $O E c o$ ficou para trás. De qualquer forma, $O E c o$ cumpriu sua missão, para a época que esteve em circulação, levando instrução para a juventude católica, por mais de cinco décadas.

\section{Seções recreativas em $O$ Eco e a Matemática}

Dentre as seções recreativas presentes no periódico $O E c o$, observou-se a Matemática na seção Recreio, desde a sua primeira edição, no ano de 1914. Posteriormente, encontrou-se a seção Para Pequenos Mathemáticos, nos anos de 1919, 1920, 1921 e 1924. No final da década

${ }^{11}$ Entrevista concedida por Luiz Osvaldo Leite, em Porto Alegre/RS, no dia 16 de março de 2018. 
de 1930, a seção Recreio apareceu com as denominações Mata Tempo Intelectual e Para o Grande Concurso, seguindo com a seção Cantinho do Sábio, em seu primeiro volume do ano de 1940, até o último de 1962.

Nessas seções recreativas ${ }^{12}$, predominavam enigmas, charadas, palavras cruzadas, perguntas, problemas e curiosidades. Prêmios, tais como livros, também eram sorteados entre os assinantes que enviavam as soluções corretas, num prazo de 30 dias após a publicação de cada edição. Geralmente, na segunda edição seguinte do periódico, eram publicados os resultados das atividades e dos concursos e os seus respectivos ganhadores. Além disso, quem quisesse poderia auxiliar no repertório, enviando contribuições para serem publicadas.

\subsection{A seção Recreio e a Matemática}

A seção Recreio apareceu desde a primeira edição de $O$ Echo, no ano de 1914, e se estendeu até 1933, por meio de enigmas, charadas e problemas. Segundo o redator, essa seção objetivava despertar e aguçar a curiosidade dos leitores, pois "o princípio educativo das charadas, como ouvi principalmente em Portugal, [...] se trata do predileto recreio das doces horas de sarau" (O ECHO, 1914, v. 3, p. 138). Na Figura 3, apresenta-se um excerto com a identificação da seção Recreio no periódico $O$ Echo:

Figura 3 - Identificação da seção Recreio

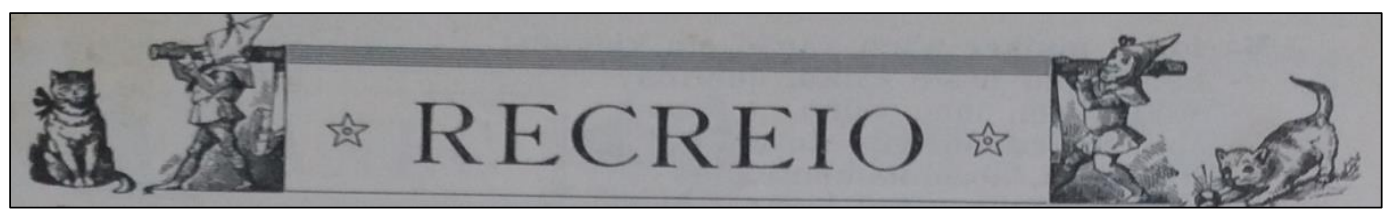

Fonte: $O$ Echo, 1915, v. 2, p. 68.

Conforme o redator, para que essa seção realmente fosse um recreio de leitores pequenos e grandes, objetivou-se satisfazê-los, trazendo charadas fáceis aos novatos e menos fáceis aos veteranos aguerridos. O redator ainda sugeria:

Olhem bem para a palavra 'Recreio'. Quem é que não gosta dela? Garanto que não há um só. Ao som mágico desse vocábulo desannuviam-se todos os rostos, e uma como que calma reconstituidora vem estender suas azas benfazejas sobre o espírito fatigado!... Todos gostam de recrearem-se, cada qual a seu modo. [...] E a devisa da nossa revista o 'Echo' é precisamente instruir recreando. Os que conhecem o 'Echo' sabem de sobejo que ele até agora seguiu rigorosamente a norma traçada, nunca deixando seu redactor de enviar esforços para fazê-lo ao mesmo tempo interessante e instrutivo. Uma secção, que muito contribúi para o interessante e o instructivo, é o "Recreio". (O ECHO, 1922, p. 57, grifo do autor) $)^{13}$.

\footnotetext{
12 Não se encontrou, no periódico, algum motivo para as alterações nas denominações dessas seções, podendo-se destacar apenas que elas deixavam de existir, sendo substituídas, em edições posteriores, por uma nova denominação e preservando a característica recreativa.

${ }^{13}$ A citação mantém sua ortografia original.
} 
Ao analisar as edições do periódico com a seção Recreio, destacaram-se os excertos que envolviam Matemática, observando-se a presença aleatória de conhecimentos de aritmética, geometria, álgebra, grandezas e medidas. Neste artigo, destacam-se dois problemas:

Problema 1: Uma lesma sobe por uma parede de 20 metros de altura. De dia faz 5 metros, de noite escorrega 4 metros. Depois de quantos dias estará em cima? (O ECHO, 1916, v. 6, p. 216).

Considerando que a lesma sobe $5 \mathrm{~m}$ durante o dia e escorrega $4 \mathrm{~m}$ durante a noite, a resolução desse problema pode ser feita por meio das seguintes relações:

$$
\begin{array}{ll}
1^{\mathrm{o}} \mathrm{dia} \rightarrow 5-4=1 \mathrm{~m} . & 2^{\mathrm{o}} \mathrm{dia} \rightarrow 1+5-4=2 \mathrm{~m} . \\
3^{\mathrm{o}} \mathrm{dia} \rightarrow 2+5-4=3 \mathrm{~m} . & 4^{\mathrm{o}} \mathrm{dia} \rightarrow 3+5-4=4 \mathrm{~m} . \\
5^{\mathrm{o}} \mathrm{dia} \rightarrow 4+5-4=5 \mathrm{~m} . & 6^{\mathrm{o}} \mathrm{dia} \rightarrow 5+5-4=6 \mathrm{~m} . \\
7^{\mathrm{o}} \mathrm{dia} \rightarrow 6+5-4=7 \mathrm{~m} . & 8^{\mathrm{o}} \mathrm{dia} \rightarrow 7+5-4=8 \mathrm{~m} . \\
9^{\mathrm{o}} \mathrm{dia} \rightarrow 8+5-4=9 \mathrm{~m} . & 10^{\circ} \mathrm{dia} \rightarrow 9+5-4=10 \mathrm{~m} . \\
11^{\mathrm{o}} \mathrm{dia} \rightarrow 10+5-4=11 \mathrm{~m} . & 12^{\mathrm{o}} \mathrm{dia} \rightarrow 11+5-4=12 \mathrm{~m} . \\
13^{\mathrm{o}} \mathrm{dia} \rightarrow 12+5-4=13 \mathrm{~m} . & 14^{\mathrm{o}} \mathrm{dia} \rightarrow 13+5-4=14 \mathrm{~m} . \\
15^{\mathrm{o}} \mathrm{dia} \rightarrow 14+5-4=15 \mathrm{~m} . & 16^{\circ} \mathrm{dia} \rightarrow 15+5=20 \mathrm{~m} .
\end{array}
$$

No $16^{\circ}$ dia, pela manhã, estava a $15 \mathrm{~m}$ de altura, avançando mais $5 \mathrm{~m}$ durante esse dia. À noitinha, atingiu o topo da parede de $20 \mathrm{~m}$ e, durante essa noite, não escorregou mais. Portanto, a lesma levou 16 dias para chegar ao topo da parede. Ressalta-se que esse enunciado também se encontra, de forma semelhante, em livros didáticos atuais.

Problema 2: Agora, veja o terreno retangular da Figura 4. É a propriedade de um velho pai, que tem 8 filhos, infelizmente bastante discordes. No centro fica a casa paterna com o único poço de água potável de todo o terreno. O velho pai pede aos amigos do Recreio de lhe dividirem o terreno em 8 partes de igual figura e superfície de tal modo, que todos tenham contato direto com o poço e a casa paterna, sem passarem por terras de um dos outros. (O ECHO, 1917, v. 6, p. 221).

Figura 4 - Terreno retangular e sua divisão em partes e formas iguais

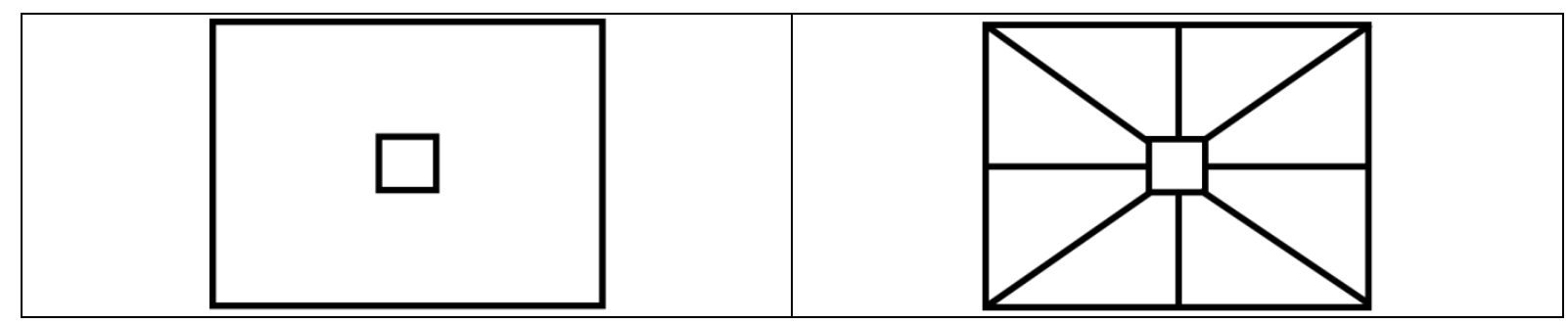

Fonte: O Echo, 1917, v. 6, p. 221.

Fonte: O Echo, 1917, v. 8, p. 293.

Observa-se que, na solução desse problema geométrico, conforme a Figura 4, unem-se os vértices correspondentes dos quadriláteros e os pontos médios dos lados paralelos, para obtenção de oito superfícies iguais em forma de trapézios retângulos. 


\title{
5.2 A seção Para Pequenos Mathemáticos
}

No ano de 1919, na $4^{\text {a }}$ edição de $O E$ Echo, nota-se a presença de um espaço destinado a pequenos matemáticos, a partir de contos e histórias matemáticas. $\mathrm{O}$ texto inicial da seção sugere:

\begin{abstract}
Reparaste no cabeçalho que hoje aparece no alto dessa página? É novo para $O$ Echo, que pelo visto quer oferecer mais uma novidade aos seus bons amigos. Bem adivinhado! Mas repare melhor: o cabeçalho só diz 'para pequenos mathemáticos'. Por isso, se sois grandes, virae a folha! Prossegui, que O Echo contém muito para vós. Isto que aqui vae é para pequenos - ou quiçá para grandes que felizmente ainda têm comprehensão para divertimentos e travessuras da infância buliçosa alegre e feliz. (O ECHO, 1919, v. 4, p. 150, grifo do autor).
\end{abstract}

Segundo o editor, escrevia-se para pequenos, e isso se verifica por meio de uma história. Seria como tocar alvorada para quem não está para acordar ${ }^{14}$. Corroborando com esse editor, Büchler (1919) enfatiza que se deve ter sempre em vista que o espírito infantil só é capaz de noções concretas, por isso se associam sempre as abstrações aritméticas a coisas que fazem sentido à criança, aliando os conceitos aritméticos a conhecimentos oriundos da experiência infantil. Portanto, o conhecimento matemático apresentado em forma de contos e histórias matemáticas contribuiria para a compreensão dos conhecimentos matemáticos.

Esse fato ficou fortemente evidenciado na proposta introduzida na seção Para Pequenos Mathemáticos. Nos volumes 4 a 10 de 1919, é contada a história de um menino travesso, mas esperto, chamado Chiquinho Mathemático. Essa história envolve o conhecimento matemático em um contexto de vivência de crianças, intitulada Chiquinho Mathemático e os noves-fora, que aborda a ideia da prova dos nove, que era uma maneira de conferir os cálculos realizados. De acordo com o volume 5 de $O$ Echo (1919), o periódico era para a mocidade estudiosa se ocupar depois de feitas as lições escolares, aos domingos e nas tardes livres, especialmente em dias chuvosos, uma vez que em dias ensolarados tinham brincadeiras ao ar livre. Portanto, a ideia dos editores do periódico era associar abstrações matemáticas a coisas que faziam sentido à criança, aliando conceitos matemáticos a conhecimentos oriundos da experiência infantil.

A partir das edições de 1920 do periódico, na seção Para Pequenos Mathemáticos, foram apresentados 63 problemas recreativos e suas possíveis soluções em edições posteriores. Observou-se uma distribuição uniforme dos problemas recreativos nas áreas da álgebra e da geometria, um predomínio de problemas envolvendo aritmética, havendo também problemas sem relação direta com a Matemática, servindo apenas como momentos de recreação. Neste artigo, destacam-se dois desses problemas:

Problema 1: Maneca e Nanico, ambos armados de boas pernas e melhores braços para trepar, foram ao quintal apanhar figos. Nenhum dos pequenos mathemáticos os viu, contudo queria que me dissessem quantos figos apanhou cada um se, ao voltarem para casa, lhes ouvi estas palavras:

Maneca: "Nanico, se me dás um dos teus, ambos teremos número igual".

Nanico: "E se tu me desses 3, ficarias só com 1/3 dos meus. (O ECHO, 1920, v. 2, p. 79).

${ }^{14}$ Pe. Germano Middeldorf S. J. (Editor do periódico O Echo, no período de 1914 a 1919). 
Em edição posterior, o periódico apenas informou que Maneca apanhou sete figos, enquanto Nanico apanhou nove figos. Essa resposta pode ser obtida por tentativa e erro ou, então, por meio de conhecimentos algébricos. Representando o número de figos que Maneca apanhou por m e o número de figos que Nanico apanhou por n, pode-se escrever o sistema com duas equações lineares e duas incógnitas, considerando as falas de Maneca e Nanico:

$$
\left\{\begin{array}{l}
\mathrm{m}+1=\mathrm{n}-1 \\
\mathrm{~m}-3=\frac{\mathrm{n}+3}{3}
\end{array}\right.
$$

Isolando $\mathrm{m}$ na $1^{\mathrm{a}}$ equação, tem-se que $\mathrm{m}=\mathrm{n}-2$, e fazendo a substituição na $2^{\mathrm{a}}$ equação e sua resolução, obtém-se:

$$
\begin{aligned}
& \mathrm{n}-2-3=\frac{\mathrm{n}+3}{3} \\
& \mathrm{n}-5=\frac{\mathrm{n}+3}{3} \quad \text { multiplicam-se os dois membros da equação por } 3 \\
& 3 \mathrm{n}-15=\mathrm{n}+3 \quad \text { soma-se } 15 \text { e subtrai-se n nos dois membros da equação } \\
& 3 \mathrm{n}-15+15-\mathrm{n}=\mathrm{n}+3+15-\mathrm{n} \\
& 2 \mathrm{n}=18 \text { então } \mathrm{n}=9 \text { figos } \\
& \text { Como } \mathrm{m}=\mathrm{n}-2 \text {, } \operatorname{logo} \mathrm{m}=9-2=7 \text { figos }
\end{aligned}
$$

Portanto, a solução do sistema é $S=\{7,9\}$ e Maneca apanhou sete figos, enquanto Nanico apanhou nove figos. E assim, de acordo com o enunciado do problema, caso Nanico dê um figo para Maneca, ambos ficarão com oito figos; ou se Maneca doar três figos para Nanico, ficará com quatro figos, o que corresponde a $1 / 3$ de 12 figos que terá Nanico.

Problema 2: O tio Pafuncio, lidando com linguiças na balança, teve a boa ou má sorte de deixar cair um de seus pesos de pedra de 40 quilos. O peso se partira em 4 pedaços. Por pouco que o tio não cuspiu cobras e lagartas contra si mesmo e mais contra o peso partido. Examinando, porém, os 4 pedaços, não pode deixar de exclamar: "Ora, que fortuna no caiporismo! Já posso dispensar os outros pesos miúdos, com só esses 4 pedaços peso todos os quilos de 1 a 40. Sempre vale o ditado: Há males que vem por bem”. Perguntas: Quem me diz quanto pesa cada pedaço? E como o tio Pafuncio arranja com os 4 os 40 pesos diferentes? (O ECHO, 1920, v. 6, p. 230).

Trata-se de um problema recreativo que envolve linguiças e os pesos utilizados, além de suas possíveis combinações para pesagem da mercadoria. Inicialmente, constatou-se que os cacos do peso do tio Pafúncio, que se partiu, pesam 1, 3, 9 e 27 quilos, pois $1+3+9+27=40$ quilos. Trata-se de uma progressão geométrica (P.G.) de quatro termos em que o primeiro termo é 1, a razão é igual a 3 e a soma desses quatro termos é 40. A descoberta do tio Pafúncio permitiu dispensar os demais pesos menores, visto que, ao combinar os cacos, obteve-se todos os pesos de 1 a 40. O Quadro 1 revela todas as 40 combinações, utilizando somente os cacos com seus respectivos pesos. 
Quadro 1 - Possibilidades utilizando os cacos de pesos

\begin{tabular}{|c|c|c|c|}
\hline \multicolumn{4}{|c|}{ Pesos dos 4 cacos: $1,3,9$ e $27 \mathrm{~kg}$} \\
\hline $1=1$ & $11=(9+3)-1$ & $21=27-9+3$ & $31=27+3+1$ \\
\hline $2=3-1$ & $12=9+3$ & $22=27-(9-3)$ & $32=27+9-(3+1)$ \\
\hline $3=3$ & $13=9+3+1$ & $23=27-(3+1)$ & $33=27+9-3$ \\
\hline $4=3+1$ & $14=27-(9+3+1)$ & $24=27-3$ & $34=27+9-(3-1)$ \\
\hline $5=9-(3+1)$ & $15=27-(9+3)$ & $25=27-3+1$ & $35=27+9-1$ \\
\hline $6=9-3$ & $16=27-(9+3)+1$ & $26=27-1$ & $36=27+9$ \\
\hline $7=(9+1)-3$ & $17=27-(9+1)$ & $27=27$ & $37=27+9+1$ \\
\hline $8=9-1$ & $18=27-9$ & $28=27+1$ & $38=27+9+(3-1)$ \\
\hline $9=9$ & $19=27-9+1$ & $29=27+(3-1)$ & $39=27+9+3$ \\
\hline $10=9+1$ & $20=27-(9+1)+3$ & $30=27+3$ & $40=27+9+3+1$ \\
\hline
\end{tabular}

Fonte: Elaborado pelos autores, 2021.

Vale ressaltar que a seção Para Pequenos Mathemáticos se fez presente em 31 edições do periódico $O$ Echo, nos anos de 1919, 1920, 1921 e 1924, não aparecendo nos anos de 1922 e de 1923 e nas edições posteriores a 1924, por razão desconhecida.

\subsection{A seção Mata Tempo Intelectual e a Matemática}

A seção Mata Tempo Intelectual foi observada em 14 edições mensais do periódico $O$ Eco, desde o volume 1 do ano de 1937 ao volume 2 de 1938. Geralmente, ocupando uma página em cada edição, essa seção apresentava: os nomes dos assinantes que remetiam soluções corretas de concursos anteriores; o nome do(a) ganhador(a) do prêmio sorteado entre os acertadores; as soluções das perguntas de edição anterior; um novo concurso de perguntas, envolvendo diferentes áreas do conhecimento; as soluções das charadas de edição anterior; e um novo concurso de charadas.

Ressalta-se que, nos volumes 3, 4 e 6 do ano de 1937, os editores do periódico explicavam como fazer e resolver charadas, pois consideravam que "entre os trabalhos recreativos poucos haverá que exercitem tanto a nossa inteligência como o charadismo. $\mathrm{E}$ quanto mais aguçado estiver o entendimento do estudante, tanto maior garantia ele adquire de avançar na vida" (O ECO, 1937, v. 3, p. 91). 
Ao analisar a seção Mata Tempo Intelectual, observaram-se mais de 10 perguntas envolvendo conhecimentos matemáticos, destacando-se duas delas neste artigo. Essas perguntas envolvem conhecimentos de aritmética, álgebra, geometria, grandezas e medidas, com resolução de problemas e atividades de raciocínio lógico.

Pergunta 1: Pense um número qualquer. Tome o dobro; acrescente 78; dívida o resultado por 2, e agora, subtraia o primeiro número que pensou. O resultado será fatalmente 39 . Como se explica isso? ( $O E C O, 1937$, v. 1, p. 28).

Sua resposta é apresentada no volume 4, do ano de 1937, e considera que somente o número 78 influi no resultado. $\mathrm{O}$ número pensado não influi, pois ele desaparece durante o cálculo. Primeiramente, o número pensado é dobrado; logo pela divisão por 2, é novamente restabelecido; por fim é subtraído, com o qual ele desaparece. Resta tão somente a divisão de 78 por 2 , que é 39 . Chamando de x o número pensado, pode-se escrever que:

$$
\begin{aligned}
& (x \cdot 2+78) \div 2-x=39 \\
& x+39-x=39 \\
& 39=39
\end{aligned}
$$

Ao pensar no número 20, por exemplo, tem-se que $\mathrm{x}=20$, logo:

$(20 \cdot 2+78) \div 2-20=118 \div 2-20=59-20=39$

Outras perguntas também podem ser feitas, substituindo-se 78 por outro número inteiro e se mantendo o enunciado restante, cujo resultado sempre será a metade do número acrescentado. Por exemplo, ao acrescentar 50, o resultado será 25 , pois:

$$
\begin{aligned}
& (x \cdot 2+50) \div 2-x=25 \\
& x+25-x=25 \\
& 25=25
\end{aligned}
$$

Pergunta 2: Papai e mamãe, acompanhados de seus filhos gêmeos Flávio e Chico, de 11 anos de idade, fazem uma expedição campo afora e chegam a um rio bastante fundo e largo. Não há ponte, mas apenas uma canoinha, capaz de carregar 75 quilos. Infelizmente, papai pesa $73 \mathrm{~kg}$, mamãe 70 e os 2 meninos juntos 74. Como poderão atravessar o rio servindo-se da canoa? (OECO, 1937, v. 5, p. 155).

Essa questão também envolve conhecimentos de possibilidades, além de raciocínio lógico. De acordo com $O E c o(1937$, v. 8), o sistema mais rápido para fazer a travessia seria:

$1^{\circ}$ ) passam os gêmeos (juntos têm $74 \mathrm{~kg}$ );

$2^{\circ}$ ) volta Flávio com a canoa (um gêmeo tem menos de $74 \mathrm{~kg}$ );

$3^{\circ}$ ) vai a mamãe sozinha $(70 \mathrm{~kg})$;

$4^{\circ}$ ) Chico volta com a canoa (um gêmeo tem menos de $74 \mathrm{~kg}$ );

$5^{\circ}$ ) Passam novamente os gêmeos (juntos têm $74 \mathrm{~kg}$ );

$6^{\circ}$ ) Flávio volta com a canoa (um gêmeo tem menos de $74 \mathrm{~kg}$ );

$\left.7^{\circ}\right)$ passa papai $(73 \mathrm{~kg})$

$8^{\circ}$ ) volta Chico (um gêmeo tem menos de $74 \mathrm{~kg}$ );

$9^{\circ}$ ) Passam os gêmeos (juntos têm $74 \mathrm{~kg}$ ). E assim, a família conseguiria atravessar o rio, com uma canoinha, capaz de carregar $75 \mathrm{~kg}$. 


\subsection{A seção Para o Grande Concurso e a Matemática}

No ano de 1938, na $3^{\text {a }}$ edição, surgiu a seção Para o Grande Concurso, em substituição à seção Mata Tempo Intelectual. A nova seção ocupava uma página do periódico $O$ Eco e sempre apresentava quatro tipos de atividades: uma caricatura, para identificação do erro; uma pergunta, envolvendo conhecimento matemático e/ou raciocínio lógico; um concurso de charadas, cujas orientações para resolução foram feitas na seção Mata Tempo Intelectual; e um concurso de palavras cruzadas.

Além disso, trazia informações sobre os assinantes que remeteram soluções corretas das atividades de edições anteriores do periódico. Ressalta-se a existência de observações, informando que somente seriam aceitas soluções de assinantes de $O E c o$, as quais deveriam ser numeradas, conforme o número de $O E c o$ e o número da pergunta do concurso. Também deveriam estar assinadas com o nome e o endereço do remetente $(O E C O, 1938$, v. 5). Na análise dessa seção, destacam-se duas perguntas envolvendo Matemática.

Pergunta 1: Quantos triângulos se encontram neste desenho (Figura 5)?

Figura 5 - Desenho com triângulos

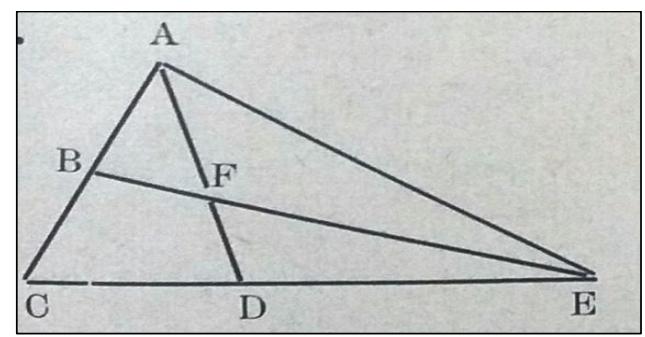

Fonte: $O E c o, 1938$, v. 3, p. 123.

Essa pergunta envolve conhecimentos geométricos e como resposta, tem-se que há oito triângulos nesse desenho, a saber: $\triangle \mathrm{ABF}, \triangle \mathrm{ABE}, \triangle \mathrm{ACD}, \triangle \mathrm{ACE}, \triangle \mathrm{AEF}, \triangle \mathrm{ADE}, \triangle \mathrm{BCE}$ e $\triangle \mathrm{DEF}$.

Pergunta 2: Num curral encontram-se coelhos e perus. Todos juntos têm 72 pés e 20 cabeças. Pergunta-se: quantos coelhos e quantos perus há no curral? $(O E C O, 1938$, v. 9, p. 285).

Representando a quantidade de coelhos por c e a quantidade de perus por $\mathrm{p}$, nesse curral, e considerando que um coelho possui 4 pés e um peru possui 2 pés, pode-se escrever e resolver o seguinte sistema com duas equações lineares:

$$
\left\{\begin{array}{l}
4 c+2 p=72 \\
c+p=20
\end{array}\right.
$$

Fazendo $\mathrm{c}=20-\mathrm{p}$ e substituindo-se na $1^{\mathrm{a}}$ equação, tem-se:

$$
\begin{aligned}
& 4 \cdot(20-p)+2 p=72 \\
& 80-4 p+2 p=72 \\
& -2 p=-8 \\
& p=4 \text { perus }
\end{aligned}
$$

Agora, basta substituir o valor encontrado para p na $2^{\mathrm{a}}$ equação, ou seja: 


$$
\begin{aligned}
& c+4=20 \\
& c=16 \text { coelhos. }
\end{aligned}
$$

Logo, no curral há 16 coelhos ( $16 \times 4=64$ pés $)$ e 4 perus $(4 \times 2=8$ pés), que juntos têm 78 pés e 20 cabeças.

A seção Para o Grande Concurso foi observada em oito edições do periódico $O$ Eco. Nos volumes 3, 5, 6, 7, 8, 9 e 10, do ano de 1938, apareceram os quatro tipos de atividades citadas, totalizando 28 atividades, cujas respostas foram apresentadas no volume 12, do mesmo ano. Em $O$ Eco $(1938$, v. 12) também se informavam os nomes dos maiores pontuadores por tipo de atividade (caricatura; pergunta; charadas; palavras cruzadas) e de mais sete menções honrosas, entre os 78 solucionadores do concurso.

\subsection{A seção Cantinho do Sábio e a Matemática}

De 1940, em seu primeiro volume, até o último de 1962, o periódico $O$ Eco trouxe a seção recreativa Cantinho do Sábio. Nessas edições, a sistemática utilizada foi a mesma: atividades sugeridas pela seção, envio da solução até 30 dias após sua publicação, divulgação das respostas em duas ou três edições posteriores, com premiação aos que acertaram todas as questões.

Ao analisar edições do periódico $O$ Eco, com a seção Cantinho do Sábio, destacaramse os excertos que envolviam Matemática, observando-se a presença de conhecimentos de aritmética, geometria e álgebra, além de problemas de raciocínio lógico.

Problema 1: Morreu certo pai que deixou a seus três filhos a herança de 11 ovelhas, com a seguinte ordem: ao primeiro caberia a metade das ovelhas; o segundo ficaria com um quarto; e o terceiro deveria contentar-se com a sexta parte dessas 11 ovelhas. Mas não poderiam matar nenhuma ovelha ao fazer a partilha. Como se arranjaram esses três irmãos? (O ECO, 1941, v. 3, p. 70).

Uma possível solução para esse problema foi encontrada em três edições posteriores do periódico. A repartição das 11 ovelhas entre os três irmãos é muito simples. Como não queriam brigar, foram procurar o juiz para dar solução ao caso. Mandou trazer mais uma ovelha sua, perfazendo o número de 12. Dividiu-as pela metade e entregou uma metade ao irmão mais velho $=6$ ovelhas, deixando o felizardo bem satisfeito. Ao segundo, mandou trazer a quarta parte das $12=3$ ovelhas, com que este se deu por bem servido. Ao terceiro, caberia a metade $=2$ ovelhas. De modo que $6+3+2+11$ ovelhas, de acordo com a vontade do pai. Isso se chama "sentença salomônica ${ }^{15}$. Quem o não sabia ainda, fique-o sabendo agora de uma vez para sempre" ( $O$ ECO, 1941, v. 6, p. 149).

Esse problema também pode ser resolvido por meio de uma divisão proporcional das 11 ovelhas, considerando-se que o irmão mais velho fica com a metade $(1 / 2)$, o seguinte com um quarto $(1 / 4)$ e o mais novo com um sexto $(1 / 6)$ delas:

$$
\frac{11}{\frac{1}{2}+\frac{1}{4}+\frac{1}{6}}=\frac{11}{\frac{6}{12}+\frac{3}{12}+\frac{2}{12}}=\frac{11}{\frac{11}{12}}=11 \cdot \frac{12}{11}=12
$$

\footnotetext{
${ }^{15}$ Rei de Israel, Salomão é um personagem bíblico que se destacou pela sabedoria na tradição da cultura judaicocristã. Uma sentença salomônica é criteriosa e sábia, mas não necessariamente agrada os envolvidos.
} 
Logo, ao irmão mais velho cabe $1 / 2$ de $12=6$ ovelhas. Ao segundo irmão, corresponde $1 / 4$ de $12=3$ ovelhas, e ao terceiro irmão, cabe $1 / 6$ de $12=2$ ovelhas. E $6+3+2=11$ ovelhas.

Problema 2: Um ladrão, tentando roubar laranjas, penetrou num pomar que estava guardado por oito vigias. Depois de ter roubado o suficiente e colocado num saco, encontrouse com um dos vigias. Este o prendeu, dizendo: Somente te soltarei, se me deixares a metade das laranjas roubadas, mais meia laranja, sem partir nenhuma. O ladrão aceitou a proposta e tentou sair. Porém, o mesmo sucedeu com todos os outros vigias, e o ladrão retirou-se do pomar com o saco completamente vazio. Quantas laranjas tinha roubado? (O ECO, 1960, v. 3, p. 144).

Para resolver esse problema, é preciso considerar que o ladrão teve que deixar metade das laranjas mais meia laranja, sem partir nenhuma, nas oito vezes que encontrou um vigia. Então, representando por x o total de laranjas roubadas, é possível escrever que o ladrão deixou:

- ao $1^{\text {o vigia: }} \frac{\mathrm{x}}{2}+\frac{1}{2}=\frac{\mathrm{x}+1}{2}$ laranjas;

- ao 2 vigia: $\frac{\mathrm{x}-\left(\frac{\mathrm{x}+1}{2}\right)}{2}+\frac{1}{2}=\frac{\mathrm{x}-1}{2} \cdot \frac{1}{2}+\frac{1}{2}=\frac{\mathrm{x}-1}{4}+\frac{1}{2}=\frac{\mathrm{x}+1}{4}$ laranjas;

- ao 3 vigia: $\frac{\mathrm{x}-\left(\frac{\mathrm{x}+1}{2}\right)-\left(\frac{\mathrm{x}+1}{4}\right)}{2}+\frac{1}{2}=\frac{\mathrm{x}-3}{4} \cdot \frac{1}{2}+\frac{1}{2}=\frac{\mathrm{x}-3}{8}+\frac{1}{2}=\frac{\mathrm{x}+1}{8}$ laranjas;

E assim, sucessivamente, observando-se que o ladrão sempre deixava a metade de laranjas entregues ao vigia precedente. Reunindo-se essas informações, pode-se compor e resolver a seguinte equação de $1^{\circ}$ grau:

$$
\begin{aligned}
& \frac{x+1}{2}+\frac{x+1}{4}+\frac{x+1}{8}+\frac{x+1}{16}+\frac{x+1}{32}+\frac{x+1}{64}+\frac{x+1}{128}+\frac{x+1}{256}=x \\
& \frac{128 x+128+64 x+64+32 x+32+16 x+16+8 x+8+4 x+4+2 x+2+x+1}{256}=\frac{256 x}{256}
\end{aligned}
$$

$255 \mathrm{x}+255=256 \mathrm{x}$

$\mathrm{x}=255$ laranjas.

Portanto, o ladrão roubou o total de 255 laranjas. A distribuição delas para os vigias foi a seguinte:

$-1^{\circ}$ vigia: $\frac{x}{2}+\frac{1}{2}=\frac{255}{2}+\frac{1}{2}=\frac{255+1}{2}=\frac{256}{2}=128$ laranjas;

$-2^{\text {o vigia: }} \frac{\mathrm{x}+1}{4}=\frac{255+1}{4}=\frac{256}{4}=64$ laranjas;

$-3^{\circ}$ vigia: $\frac{x+1}{8}=\frac{255+1}{8}=\frac{256}{8}=32$ laranjas;

$-8^{\circ}$ vigia: $\frac{x+1}{256}=\frac{255+1}{256}=\frac{256}{256}=1_{\text {laranja. }}$ 
Observa-se que essa distribuição de laranjas aos vigias forma uma progressão geométrica (P. G.) decrescente de razão q =1/2, ou seja, $(128,64,32,16,8,4,2,1)$, cuja soma de seus oito termos é 255. Logo, o ladrão terminou sua ação sem nenhuma laranja.

Depois de expor os principais conhecimentos matemáticos presentes nas seções recreativas do periódico $O E c o$, apresentam-se as considerações finais deste estudo e suas contribuições para Educação Matemática.

\section{Considerações finais}

Este artigo propôs-se a analisar edições do periódico ilustrado $O E c o$, com ênfase para a Matemática nas seções recreativas: Recreio (1914-1933); Para Pequenos Mathemáticos (1919-1921 e 1924); Mata Tempo Intelectual (1937-1938); Para o Grande Concurso (1938) e Cantinho do Sábio (1940-1962). Ressalta-se que o material analisado evidencia relevantes contribuições da ordem dos Jesuítas na formação da sociedade gaúcha e brasileira.

Nas seções recreativas, foram encontradas perguntas, charadas, problemas, enigmas, curiosidades, palavras cruzadas e outras atividades de passatempo, envolvendo diferentes áreas do conhecimento. Ao mesmo tempo em que representavam um espaço de lazer para seus leitores, essas seções também traziam ensinamentos morais e religiosos, além de conhecimentos de formação geral. A Matemática, por exemplo, está presente em perguntas, problemas e curiosidades, valorizando o pensamento lógico-matemático dos leitores com desafios e premiando assinantes com as soluções corretas.

Os conhecimentos matemáticos envolvidos nessas seções estão relacionados com diferentes conteúdos, tais como: operações aritméticas fundamentais, critérios de divisibilidade, expressões numéricas, frações, razão entre grandezas, transformação entre unidades de medidas, progressões, possibilidades, formas geométricas, equações de $1^{\circ}$ grau, sistemas com duas equações lineares e funções do $1^{\circ}$ grau.

Portanto, os conhecimentos matemáticos envolvem aritmética, geometria, álgebra, grandezas e medidas, com foco no desenvolvimento de habilidades para cálculo, raciocínio lógico e resolução de problemas, envolvendo situações de forma instigante, provocativa e útil. Por meio dessas seções recreativas, os editores de $O$ Eco buscavam despertar o interesse e a curiosidade da juventude estudantil, contribuindo para a circulação do periódico e a formação da juventude católica nos colégios onde o mesmo circulava.

O estudo da Matemática presente nas seções recreativas do periódico $O$ Eco, publicado no século passado, permitiu investigar uma cultura, num lugar e num tempo determinados, contribuindo, assim, para a História da Educação Matemática e o ensino de Matemática em diferentes níveis. Ressalta-se que os problemas e perguntas apresentados neste artigo são atividades que podem ser adaptadas e aproveitadas para aulas de Matemática na Educação Básica e na formação inicial e continuada de professores, pelo seu foco no desenvolvimento do pensamento lógico-matemático.

\section{Referências}

BRITTO, Silvio Luiz Martins. O ensino da aritmética nas escolas paroquiais católicas e no Ginásio Conceição, sob a ótica dos Jesuítas nos séculos XIX e XX. 2016. Tese (Doutorado em Ensino de Ciências e Matemática) - Universidade Luterana do Brasil, Canoas, 2016. 
BRITTO, Silvio Luiz Martins; BAYER, Arno; KUHN, Malcus Cassiano Kuhn. A contribuição dos Jesuítas para o ensino da Matemática no Rio Grande do Sul. São Leopoldo, RS: UNISINOS, 2020.

BÜCHLER, Georg Augusto. Arithmetica Elementar. Livro I. São Paulo: Weiszflog Irmãos, 1919.

CATANI, Denice Bárbara; BASTOS, Maria Helena Camara (org.). Educação em revista: A imprensa periódica e a história da educação. São Paulo: Escrituras, 1997.

CELLARD, A. A análise documental. In: POUPART, Jean et al. A pesquisa qualitativa: enfoques epistemológicos e metodológicos. Petrópolis/RJ: Vozes, 2008.

CERTEAU, Michel de. A escrita da História. Tradução: Maria de Lourdes Menezes. Rio de Janeiro: Forense Universitária, 1982.

COLÉGIO ANCHIETA. Cem anos. Porto Alegre, 1990.

COLÉGIO ANCHIETA. Relatório. Porto Alegre, 1914.

HERNANDEZ DIAZ, José María (org.). La prensa de los escolares y estudiantes: su contribucion al patrimonio historico educativo. Salamanca: Ediciones Universidad de Salamanca, 2015.

KREUTZ, Lúcio. O professor paroquial: magistério e imigração alemã. Porto Alegre: UFRGS; Caxias do Sul: EDUCS, 1991.

KREUTZ, Lúcio. Material didático e currículo na escola teuto-brasileira. São Leopoldo: UNISINOS, 1994.

KUHN, Malcus Cassiano. O ensino da matemática nas escolas evangélicas luteranas do Rio Grande do Sul durante a primeira metade do século XX. 2015. Tese (Doutorado em Ensino de Ciências e Matemática) - Universidade Luterana do Brasil, Canoas, 2015.

KUHN, Malcus Cassiano; BAYER, Arno. A matemática nas escolas paroquiais luteranas gaúchas do século XX. Canoas: ULBRA, 2017a.

KUHN, Malcus Cassiano; BAYER, Arno. O contexto histórico das escolas paroquiais luteranas gaúchas do século XX. Canoas: ULBRA, 2017b.

LEITE, Luiz Osvaldo. Jesuítas cientistas no sul do Brasil. São Leopoldo: UNISINOS, 2005.

LEITE, Luiz Osvaldo. A revista $\boldsymbol{O}$ Eco e sua trajetória. Porto Alegre/RS, 16 mar. 2018. Estágio Pós-doutoral em Programa de Pós-Graduação. Entrevista concedida a Silvio Luiz Martins Britto.

MAURO, Suzeli. Uma história da matemática escolar desenvolvida por comunidades de origem alemã no Rio Grande do Sul no final do século XIX e início do século XX. 2005. 
Tese (Doutorado em Educação Matemática) - Universidade Estadual Paulista, Rio Claro, 2005.

O ECHO: revista ilustrada para a mocidade estudiosa. Typographia do Centro: Porto Alegre, 1914-1931.

O ECO: revista ilustrada para a mocidade brasileira. Tipografia do Centro: Porto Alegre, 1932-1969.

PRODANOV, Cleber Cristiano; FREITAS, Ernani Cesar de. Metodologia do trabalho científico: Métodos e Técnicas da Pesquisa e do Trabalho Acadêmico. 2. ed. Novo Hamburgo: FEEVALE, 2013.

PROST, Antoine. Doze lições sobre a História. Belo Horizonte: Autêntica, 2008.

RAMBO, Arthur Blásio. A escola comunitária teuto-brasileira católica. São Leopoldo: UNISINOS, 1994.

RAMBO, Arthur Blásio. A escola comunitária teuto-brasileira católica: a associação de professores e a escola normal. São Leopoldo: UNISINOS, 1996.

SERRA, Áurea Esteves. As associações de alunos das escolas normais do Brasil e de Portugal: apropriação e representação (1906-1927). 2010. Tese (Doutorado em Educação) Universidade Estadual Paulista, Marília, 2010.

VALENTE, Wagner Rodrigues. História da Educação Matemática: interrogações metodológicas. REVEMAT - Revista Eletrônica de Educação Matemática, Florianópolis, v. 2.2, p. 28-49, 2007.

WANDERER, Fernanda. Escola e Matemática Escolar: mecanismos de regulação sobre sujeitos escolares de uma localidade rural de colonização alemã no Rio Grande do Sul. 2007. Tese (Doutorado em Educação) - Universidade do Vale do Rio dos Sinos, São Leopoldo, 2007.

WEIDUSCHADT, Patrícia. O Sínodo de Missouri e a educação pomerana em Pelotas e São Lourenço do Sul nas primeiras décadas do século XX: identidade e cultura escolar. 2007. Dissertação (Mestrado em Educação) - Universidade Federal de Pelotas, Pelotas, 2007.

WEIDUSCHADT, Patrícia. A revista 'O Pequeno Luterano' e a formação educativa religiosa luterana no contexto pomerano em Pelotas - RS (1931-1966). 2012. Tese (Doutorado em Educação) - Universidade do Vale do Rio dos Sinos, São Leopoldo, 2012.

Recebido em dezembro de 2020.

Aprovado em maio de 2021. 